\title{
Gowers' Queen Square Case Notes on Chorea: A 21st Century Re-Appraisal
}

\author{
Thiago Cardoso Vale ${ }^{a}$ Philip George Glass ${ }^{c, d}$ Andrew Lees ${ }^{d, e}$ Francisco Cardoso $^{\text {b }}$ \\ ${ }^{a}$ Neurology Division, University Hospital, and ${ }^{\mathrm{b}}$ Movement Disorders Unit, Neurology Division, Department of Internal \\ Medicine, Faculty of Medicine, Federal University of Minas Gerais, Belo Horizonte, and 'Department of Neurology, \\ University of Campinas, UNICAMP, Campinas, Brazil; ${ }^{d}$ Institute of Neurology, Reta Lila Weston Institute of Neurological \\ Studies, University College London and ${ }^{\mathrm{e} T h e}$ National Hospital for Neurology and Neurosurgery, London, UK
}

\section{Key Words}

Sydenham's chorea - William Richard Gowers •

Huntington's disease

\begin{abstract}
Objective: To analyze the case notes of 127 patients with chorea admitted to the National Hospital at Queen Square, London, under the care of William Richard Gowers and review his contribution to the study of choreas. Methods: We consulted the case books available at the Queen Square Library, from 1878 to 1911, comprising 42 volumes. Results: 97 patients (76.3\%) were female and the age of presentation ranged from 4 to 60 years (mean 14.3). 43 patients (33.8\%) experienced recurrent attacks of chorea. 29 patients (22.8\%) had a family history of chorea. Past history of rheumatic fever was observed in 46 patients (36.2\%). 54 patients (42.5\%) had speech impairment while a similar number had a cardiac murmur. Generalized chorea occurred in $87.4 \%$ and hemichorea in $11.8 \%$. Gowers diagnosed different forms of chorea: Huntington's disease, paralytic, persistent, recurrent, tetanoid, functional, maniacal, hemichorea and chorea gravidarum. Conclusions: Gowers was one of the pioneers in recognizing chorea as a physical sign found in a myriad of etiologies. He also provided a comprehensive description of the clinical features and natural history of Sydenham's chorea in his work.

Copyright $\odot 2012$ S. Karger AG, Basel
\end{abstract}

\section{Introduction}

In the last quarter of the 19th century, Jean-Martin Charcot (1825-1893) [1-3] and his contemporary Silas Weir Mitchell (1829-1914) [1, 4, 5] provided important insights into the knowledge of chorea. Charcot contributed with the description of chorea and differential diagnosis, but failed to achieve substantial insight into the different etiological factors that now clearly separate Sydenham's chorea (SC) from Huntington's disease (HD), described in 1872 [6]. Charcot was aware of the lack of solidity in the classification in 1884 when he delegated his assistant Georges Gilles de la Tourette (1857-1904) to 'sort out the chaos of the choreas' leading to his classical paper on 'maladie des tics convulsifs' [3, 7]. Mitchell's pioneering epidemiological works in Philadelphia described the relation of chorea to meteorological conditions, seasons, urban and rural localities [5].

William Richard Gowers (1845-1915) worked at the National Hospital for the Relief and Cure for the Paralyzed and Epileptic at Queen Square, in London, from

This work was presented as a platform at the American Academy of Neurology's Annual Meeting 2012, New Orleans, La., USA, and also as a Poster at the 16th International Congress of Parkinson's Disease and Movement Disorders, Dublin, Ireland.

\section{KARGER}

Fax +41613061234 E-Mail karger@karger.ch www.karger.com
(C) 2012 S. Karger AG, Basel

0014-3022/13/0691-0048\$38.00/0

Accessible online at:

www.karger.com/ene
Francisco Cardoso

Avenida Pasteur 89/1107

Belo Horizonte, MG 30150-290 (Brasil)

E-Mail cardosofe@terra.com.br 
1870 , where he was associated with for the rest of his career (fig. 1) $[8,9]$. Gowers' name is now primarily remembered for his 'Manual of the Disease of the Nervous System', the first edition which appeared in two volumes, published in 1886 and 1888 [10-12]. In his textbook, there is a lengthy description of chorea, in particular SC, based mainly on his observations on 120 children and young adults admitted at the National Hospital and the many more he had seen in his outpatient clinics.

Based on a review of the case notes from the National Hospital, we describe the most frequent types of chorea encountered by Gowers and compare his descriptions with the current state-of-the-art knowledge of the disease.

\section{Methods}

We consulted the volumes of Gowers' case notes available at the Queen Square Library, Archive and Museum, National Hospital for Neurology and Neurosurgery, in London (UK), from 1878 to the time of his retirement (1911), comprising 42 volumes and 2,478 patients. Nineteen different categories were listed in order to classify the most common diagnoses: epilepsy, cerebrovascular disorders, neoplasm, functional disorders, neurasthenia, disseminated sclerosis, motor neuron disease, neuromuscular disease, peripheral nervous system disease, spinal cord disease, syphilis, tabes dorsalis, chorea, tremor, tic, paralysis agitans, ataxia, dystonia and others. All case notes on chorea were sufficiently legible and the following data were collected: age, gender, dates of admission, readmission and discharge, duration of illness, past medical history, present history and physical examination, comorbidities, predisposing factors, family history, form of presentation, predominant affected body segment, chorea's severity, impairment of cognition, speech and swallowing, nutritional status and cardiac compromise (fig. 2). The study was conducted according to ethical standards of the Queen Square Library, Archive and Museum, National Hospital for Neurology and Neurosurgery, London, UK.

\section{Results}

The most common recorded diagnoses were epilepsy (14.9\%), followed by spinal cord disease $(10.3 \%)$, cerebrovascular disorders (9.4\%), functional disorders (7.9\%) and neoplasm (7.7\%). A movement disorder was diagnosed in 188 cases (7.6\%). Of 2,478 cases, 127 (5.1\%) received the diagnosis of chorea, the most common movement disorder encountered by Gowers, accounting for almost threequarters of this category admissions (67.6\%). Of 188 cases of a movement disorder, the diagnosis of ataxia, paralysis agitans, tic disorders, dystonia and tremor were held in,

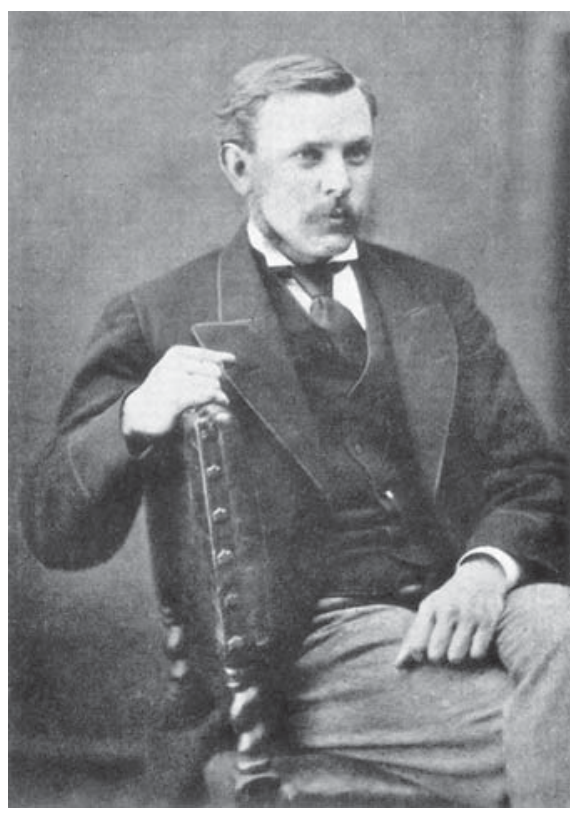

Fig. 1. William Gowers at the age of 29 years - one of the few pictures which exist showing him without a beard.

respectively, 11.7, 9.0, 4.8, 4.2 and $2.7 \%$. No cases of chorea were admitted in 1881, 1887 and 1911. The number of case notes per volume ranged from 2 to 175 (mean 79.9). Gowers reported most of his case notes during the years of $1897-1909$, when $68 \%$ of the notes were gathered with a mean of 129.7 cases per year.

Among the 127 cases of chorea, 97 (76.3\%) were female, determining a female:male ratio of 3.2:1. Most of the patients were children and young adults. Ages ranged from 4 to 60 years (mean 14.3). 43 patients (33.8\%) experienced recurrent attacks of chorea, and $14(11 \%)$ of them had more than three attacks. 29 patients (22.8\%) had a family history of chorea. Past history of rheumatic fever was observed in 46 patients (36.2\%). Other illnesses such as chickenpox, influenza, whooping cough, typhoid and diphtheria affected 59 patients (46.4\%). 16 of the cases $(12.5 \%)$ were described as poorly nourished and thin. 34 patients $(26.7 \%)$ presented with chorea shortly after an emotional event or fright. 54 patients (42.5\%) had speech impairment, and a similar proportion had a cardiac murmur. 11 patients (8.6\%) developed swallowing difficulties whereas only 5 (3.9\%) were found to have cognitive or behavior problems. 15 patients $(11.8 \%)$ had weakness on neurological examination. The vast majority of the chorea cases were generalized (87.4\%) whereas hemichorea occurred in 15 patients (11.8\%) and chorea restricted to a 


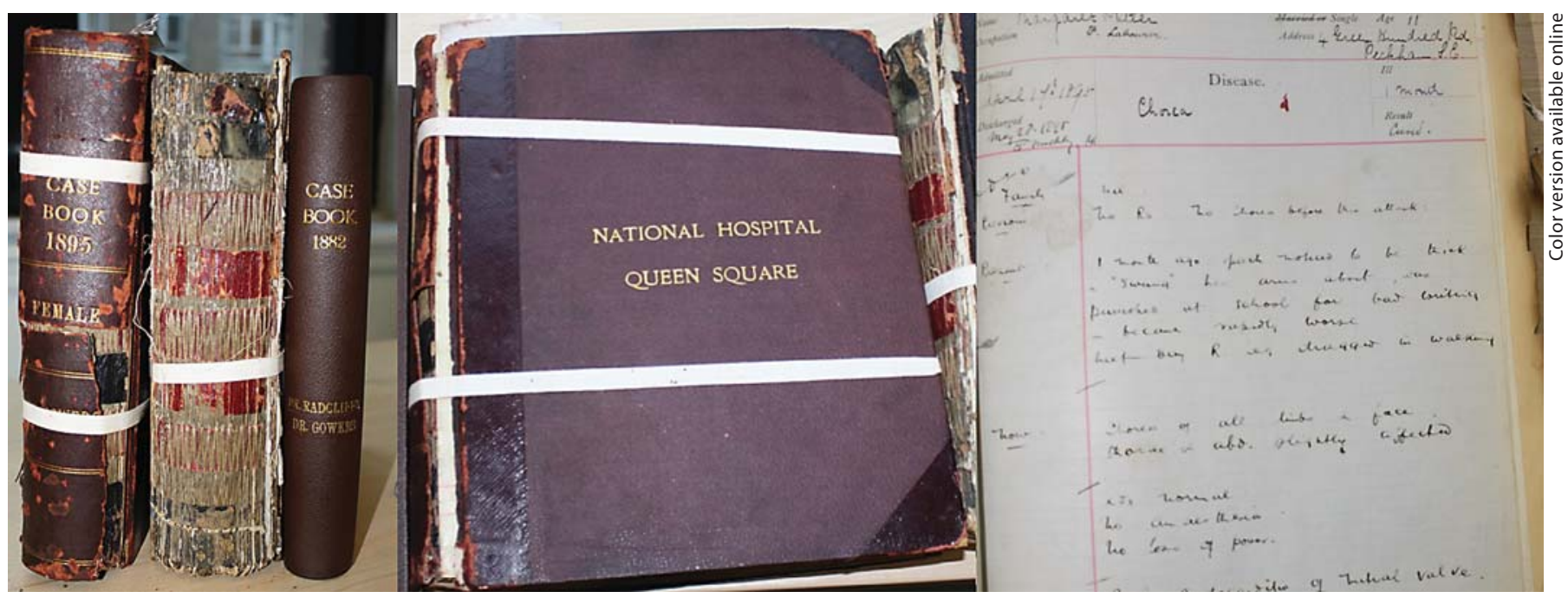

Fig. 2. Gowers' case notes volume and an inpatient front sheet with a diagnosis of chorea (images courtesy of the Queen Square Library, Archive and Museum. Copyright National Hospital for Neurology and Neurosurgery).

limb occurred in only 1 patient. Two of his choreic patients died, the causes being unregistered in the notes.

The diagnosis on the inpatient front sheet was 'chorea' and all but 12 of these (9.5\%) were presumed to have postinfectious chorea, most probably SC (90.5\%). 3 SC cases occurred during pregnancy and 1 was diagnosed as paralytic SC. Gowers further described 3 cases of recurrent chorea (2.3\%), 2 of maniacal chorea (1.6\%), 1 of senile hemichorea $(0.7 \%)$ and 1 of HD. He also described a child with 'tetanoid chorea', a diagnosis that was later revised to hepatolenticular degeneration following further clinical pathological studies by his clinical assistant Kinnier Wilson (1878-1937). Functional chorea was diagnosed in 4 patients (3.1\%), 3 of them female (75\%) with a mean age of onset of $19.5 \pm 5.0$. Out of 115 presumed SC cases, 91 $(79.1 \%)$ were female and the mean age was of $13.2 \pm 4.5$. (Some excerpts of cases are included in the case vignettes as article online supplementary case vignettes, www. karger.com/doi/10.1159/000343628.)

\section{Discussion}

Gowers' case notes present a unique opportunity to track the changes in thinking related to the choreas in the late 19th and early 20th centuries. The first conclusion of the review of Gowers' notes is that chorea was the most common movement disorder identified in his patients, accounting for $5 \%$ of all admissions. This is in keeping with what occurred in other medical facilities in London at that time. In a British pediatric hospital, chorea was the fourth most frequent cause of admission between 1860 and 1900 , and in the 1880 s temporarily became the second most frequent diagnosis among inpatients [13].

A second important lesson from Gowers' notes is the recognition that chorea is a syndrome with different causes. In fact, he was one of the first physicians to come to such a conclusion. William Osler (1849-1919) expressed the difficulties in establishing differential diagnoses among patients with chorea: 'in the whole range of medical terminology, there is no such olle podrida as chorea, which for a century has served as a sort of nosological pot into which authors have cast indiscriminatively' [14]. In Gowers' series, SC accounted for at least $90.5 \%$ of cases, making it the most common movement disorder in Victorian London. The incidence of SC has declined in recent years and the few cases now seen at the National Hospital almost all are in immigrants. Nevertheless, SC remains the most common cause of acute chorea in children worldwide [15]. According to a study from Pennsylvania, SC accounts for almost $100 \%$ of acute cases of chorea seen in children [16]. Gowers also differentiated HD from SC, a distinction that had eluded Charcot [6]. Gowers described 'senile chorea', which probably corresponded to vascular chorea since hemichorea with abrupt onset almost invariably is associated with stroke [15]. Of a noteworthy mention, Gowers, as well as other authors such as Charcot and Raymond, used the term 'senile chorea' to 
describe a chronic form of chorea with progressive cognitive and behavioral decline that irreversibly led to death. Therefore, this case presented in his notes might have been misdiagnosed or was indeed poorly documented, without any mention to cognitive decline, family history or previous symptoms. Gowers diagnosed maniacal chorea in 2 young female patients who developed psychosis during an acute attack of chorea. Although psychiatric complications are common in SC, psychosis is rare $[15$, 17]. Most likely, these cases had chorea due to systemic lupus erythematous rather than SC. Deservedly, hepatolenticular degeneration is associated with the name of Kinnier Wilson. Nevertheless, prior to him, Gowers was able to diagnose tetanoid chorea in 1 patient who presented with chorea and dystonia. Four patients were diagnosed as having functional chorea, which would now be termed a psychogenic movement disorder. Diagnosis of the latter is a challenging task depending on, among others, ruling out alternative causes. It remains open to discussion whether these patients of Gowers' might have other hitherto unrecognized conditions. However, it is clear that they corresponded to a small fraction of cases, a finding mirrored by contemporary data. For instance, in a recent series of pediatric psychogenic movement disorders, chorea accounted just for $0.6 \%$ of the cases [18]. Finally, Gowers labeled 3 patients as having recurrent chorea. As we now know that there is a mean recurrence rate of $20 \%$ in SC, it is possible that these patients had rheumatic fever $[15,16,19]$. In fact, this concept was already emerging in the 19th century: the British pediatric hospital data on recurrence rate was of $10 \%$ of cases whereas in Gowers' case notes it was of 33.8\% [13]. However, because other conditions, such as lupus, moyamoya disease, genetic illnesses and others may present with recurrent chorea [15], we chose to consider these subjects as belonging to a separate etiological category.

Gowers' precision of observation and lucid descriptions in his publications on chorea and in the Manual increased awareness of the variable presentation of SC and its natural history [12]. Indeed, all his clinical observations were confirmed by subsequent studies. The female predominance, the pubertal-onset, the typical pattern of movements, and factors related to worsening and subsiding were meticulously reported in Gowers' case notes. In 1881, Gowers reported 5 cases of paralytic chorea, in which asymmetrical muscular weakness was a dominant feature [20]. The choreic movements became more conspicuous as muscular power recovered. Severely decreased muscle tone is now relatively rare $(8 \%$ of all patients seen at the Movement Disorders Clinic of the Fed- eral University of Minas Gerais), but may be so pronounced that the patient becomes bedridden [15].

Many of Gowers' patients were noted to have a 'disinclination to speak'. It is now recognized that there is a decreased verbal fluency with reduced phonetic output [21-23]. Behavioral abnormalities were also emphasized in his description of SC. In his case notes, 1 patient with SC presented with 'dullness and depression', possibly depressed mood or even apathy due to frontal lobe dysfunction. Gowers also described some of the patients as being easily excitable and mentally weak, with poor scholastic achievement. Attention deficits and obsessive-compulsive behavior are now considered common in patients with SC, occurring in up to $30 \%$ of cases, and there are rare reports of psychosis and trichotillomania during the acute phase of the illness [15, 24-27].

Gowers diagnosed 3 patients with chorea during pregnancy, now referred to as chorea gravidarum [28], and he also described examples of recurrent and persistent chorea. Currently, these forms of chorea are recognized as variants of SC [15].

Since the first description by Thomas Sydenham [29], many etiologies and predisposing factors for SC have been suggested. Gowers was also interested in possible triggers for the onset of chorea and in almost a third of his inpatients, a history of fright or emotional stress was considered as a possible explanation to the recurrence or exacerbation of chorea. Signs of arthritic involvement were common as well as evidence of heart disease with cardiac murmurs. The rheumatic and cardiac involvements were probably underestimated at that time due to the lack of adequate methods of measurement. Based on these findings, Gowers speculated that a relationship between rheumatic fever, cardiac murmur and SC existed [10-12]. This would later be confirmed in the years of 1931 (when rheumatic fever was definitely linked to streptococcal infection), 1944 (Duckett Jones' criteria were first proposed), and 1956, when Taranta et al. established the link of streptococcal infection with chorea [15].

In the light of the contribution of Gowers' to the field, Osler's eulogy to him in the monograph 'On Chorea and Choreiform Affections' [14] is justified: 'To the profession of the United States and Canada you stand as the most brilliant exponent of the complex science of neurology. Please accept the dedication of this little volume as an earnest of the gratitude felt towards you by thousands of your kinsmen across the water, and as an expression of the personal attachment of your sincere friend.' 


\section{Conclusion}

This review of the case notes on chorea at the National Hospital, Queen Square, shows that Gowers description of the phenomenology and natural history of chorea is in keeping with current notions about SC. Chorea to Gowers was a physical sign with SC being the most common cause. Motor and non-motor clinical features of SC, spontaneous remission and persistence as well as its relationship with low standards of living are clearly described in his notes.

\section{Acknowledgments}

We would like to express our gratitude to all the staff at the Queen Square Library (formerly the Rockefeller Medical Library), National Hospital for Neurology and Neurosurgery, in London.
In particular, Jackie Cheshire was of paramount importance in spending her energy, time and patience in getting all those extravolumes case notes. We would also like to thank Derek Tutssel, Head of the Medical Illustration Service, for his invaluable help with Gowers' rare beardless picture.

\section{Disclosure Statement}

Thiago Cardoso Vale and Philip George Glass have nothing to disclose. Prof. Francisco Cardoso received honoraria from Boehringer Ingelheim, Novartis and Roche as well as research support from FAPEMIG. Prof. Andrew Lees received honoraria from Novartis, Teva, Meda, Boehringer Ingelheim, GSK, Ipsen, Lundbeck, Allergan, and Orion. The authors have no conflicts of interest/ financial disclosure related to the present submission and did not receive any funds for this study.

\section{References}

1 Goetz CG: Jean-Martin Charcot and Silas Weir Mitchell. Neurology 1997;48:11281132.

$\checkmark 2$ Pappert EJ: Training opportunities for the nineteenth century neurologist. Neurology 1995;45:1771-1776

3 Goetz CG, Bonduelle M, Gelfand T: Charcot: Constructing Neurology. New York, Oxford University Press, 1995.

4 Goetz CG, Pappert EJ: Early American professorships in neurology. Ann Neurol 1996; 40:258-263.

5 Mitchell SW: Lectures on Diseases of the Nervous System, Especially in Women. Philadelphia. Henry C. Lea’s Sons \& Co, 1881.

6 Goetz CG: William Osler: on Chorea: on Charcot. Ann Neurol 2000;47:404-407.

$\checkmark 7$ Lees AJ: Georges Gilles de la Tourette: the man and his times. Rev Neurol (Paris) 1986; 142:808-816.

8 Critchley M: Sir William Gowers 1845-1915: A Biographical Appreciation. London, Heinemann Medical, 1949.

-9 Holmes SG: Sir William Gowers at the National Hospital. BMJ 1951;2:1397-1398.

10 Gowers WR: A Manual of Diseases of the Nervous System. London, J\&A Churchill, 1886.

11 Gowers WR: Lectures on the Diagnosis of Diseases of the Brain. London, J\&A Churchill, 1887.
12 Gowers WR: A Manual of Diseases of the Nervous System, Vol II: Brain. Cranial Nerves. General and Functional Diseases of the Nervous System. London, J\&A Churchill, 1888.

13 Martino D, Tanner A, Defazio G, et al: Tracing Sydenham's chorea: historical documents from a British paediatric hospital. Arch Dis Child 2005;90:507-511.

14 Osler W: On Chorea and Choreiform Affections. Philadelphia, Blakiston, 1894.

$>15$ Cardoso F, Seppi K, Mair KJ, Wenning GK, Poewe W: Seminar on choreas. Lancet Neurol 2006;5:589-602.

16 Nausieda PA, Grossman BJ, Koller WC, et al Sydenham's chorea: an update. Neurology 1980;30:331-334.

17 Teixeira AL Jr, Maia DP, Cardoso F: Psycho sis following acute Sydenham's chorea. Eur Child Adolesc Psychiatry 2007;16:67-69.

18 Thomas M, Jankovic J: Psychogenic movement disorders: diagnosis and management. CNS Drugs 2004; 18:437-452.

19 Cardoso F, Silva CE, Mota CC: Sydenham's chorea in 50 consecutive patients with rheumatic fever. Mov Disord 1997;12:701-703.

20 Gowers WR: On paralytic chorea. BMJ 1881; 636-637.

-21 Cunningham MC, Maia DP, Teixeira AL Jr, Cardoso F: Sydenham's chorea is associated with decreased verbal fluency. Parkinsonism Relat Disord 2006;12:165-167.

-22 Oliveira PM, Cardoso F, Maia DP, Cunningham MC, Teixeira Jr AL, Reis C: Acoustic analysis of prosody in Sydenham's chorea. Arq Neuropsiquiatr 2010;68:744-748.
23 Beato R, Maia DP, Teixeira AL Jr, Cardoso F: Executive functioning in adult patients with Sydenham's chorea. Mov Disord 2010;25: 853-857.

24 Kummer A, Maia DP, Cardoso F, Teixeira AL: Trichotillomania in acute Sydenham's chorea. Aust NZ J Psychiatry 2007;41:10131014.

25 Teixeira AL, Athayde GR, Sacramento DR, Maia DP, Cardoso F: Depressive and anxiety symptoms in Sydenham's chorea. Mov Disord 2007;22:905-906.

-26 Maia DP, Teixeira AL Jr, Quintão Cunningham MC, Cardoso F: Obsessive-compulsive behavior, hyperactivity, and attention deficit disorder in Sydenham chorea. Neurology 2005;64:1799-1801.

27 Swedo SE, Leonard HL, Garvey M, et al: Pediatric autoimmune neuropsychiatric disorders associated with streptococcal infections: clinical description of the first 50 cases. Am J Psychiatry 1988;155:264-271.

28 Maia DP, Fonseca PG, Camargos ST, Pfannes C, Cunningham MC, Cardoso F: Pregnancy in patients with Sydenham's chorea. Parkinsonism Relat Disord 2012;18:458-461.

29 Sydenham T: On St Vitus's dance. The works of Thomas Sydenham, MD. Translated from the Latin edition of Dr. Greenhill with a life of the author by R.G. Latham, MD, Vol 2. London, The Sydenham Society, 1850, pp 257-259. 